Check for updates

Cite this: J. Mater. Chem. A, 2019, 7, 15933

Received 23rd February 2019 Accepted 19th May 2019

DOI: $10.1039 / c 9 t a 02054 c$

rsc.li/materials-a

\section{Dynamic covalent urea bonds and their potential for development of self-healing polymer materials $\uparrow$}

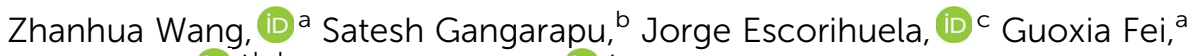 \\ Han Zuilhof (D)*bd and Hesheng Xia (D) *a
}

\begin{abstract}
Self-healing polymer materials have drawn rapidly increasing interest over the last decade, and have been studied and used in an ever-increasing range of applications. Herein, we successfully make the covalent urea bond - a pinnacle of stability due to strong resonance effects - dynamic in nature through mediation of zinc salts. The dynamic covalent character of urea in the presence of zinc ions is confirmed through dissociation reaction experiments and quantum chemical calculations of small-molecule model urea compounds. In line with our experiments, the modelling results suggest that the presence of zinc ions speeds up the reaction of urea dissociation by two orders of magnitude via the formation of $\mathrm{O}$ bound $\mathrm{Zn}$ complexes. Based on such dynamic covalent urea bonds, we then develop a novel class of self-healing polymer materials with excellent healing efficiencies. Different kinds of self-healing and reprocessable polyurea materials were prepared, with polymer properties that can be easily tuned by varying the degree of crosslinking and the molecular weight of the siloxane precursor. Since different kinds of self-healing polyurea materials could easily be prepared due to the commercial availability of a very wide range of amine and isocyanate monomers, this introduction of self-healing properties is expected to have significant potential in a range of applications, such as coatings, paints, and 3D printing. In addition, this introduces polyureas and other urea-containing polymers as a class of highly stable, yet easily reprocessable plastics, which is highly relevant given the globally desired more sustainable use of plastics.
\end{abstract}

\section{Introduction}

The attractiveness of thermoset polymer materials lies in their high stability. However, a resulting challenge therefore typically is that they cannot be reprocessed or repaired upon mechanical damage, which eventually causes environmental pollution, and the lack of repair options limits their lifetime. Endowing polymer materials with self-healing properties can solve this problem and meet sustainable development criteria. Up to now, repairable polymer systems have been realized with reversible ${ }^{1}$ or irreversible ${ }^{2,3}$ covalent bonds, supramolecular interactions, ${ }^{4}$ chemo-mechanical features ${ }^{5-7}$ and/or shape memory. ${ }^{8-11}$ In addition, recent studies have also shown that van der Waals forces $^{12}$ as well as microphase separation ${ }^{13}$ in thermoplastic

\footnotetext{
${ }^{a}$ State Key Laboratory of Polymer Materials Engineering, Polymer Research Institute, Sichuan University, Chengdu 610065, P. R. China.E-mail:xiahs@scu.edu.cn

${ }^{b}$ Laboratory of Organic Chemistry, Wageningen University, Stippeneng 4, 6708 WE Wageningen, The Netherlands. E-mail: Han.Zuilhof@wur.nl

${ }^{c}$ Department of Applied Thermodynamics, Universitat Politècnica de València, Camino de Vera $s / n, 46020$ Valencia, Spain

${ }^{d}$ Department of Chemical and Materials Engineering, King Abdulaziz University, Jeddah, Saudi Arabia
}

$\dagger$ Electronic supplementary information (ESI) available. See DOI: $10.1039 / \mathrm{c} 9 \mathrm{ta} 02054 \mathrm{c}$ polymers can also facilitate self-healing without elaborate chemical modifications. Among these methods, the use of dynamic covalent bonds ${ }^{14-18}$ to prepare self-healing polymer materials is widely studied, since no external event needs to take place, and the self-healing process can be repeated several times.

A lot of dynamic covalent bonds or structures have been successfully utilized to prepare self-healing polymer materials, including alkoxyamine-aldehyde bonds, ${ }^{19}$ Diels-Alder reaction products, ${ }^{20,21}$ thiol and selenol radical species amenable to radical association-dissociation, ${ }^{22-27}$ bond-exchanging vitrimers, ${ }^{28}$ and so on. ${ }^{29}$ The most widely used method to prepare self-healing polymer materials based on dynamic covalent chemistry $^{30,31}$ is the condensation-polymerization of a chain extender, cross-linker and small molecules containing dynamic covalent bonds. However, the introduction of new dynamic bonds increases the complexity of chemical synthesis and may also alter the original polymer properties in undesirable ways. In contrast, if one is able to impart dynamic characteristics to conventional chemical bonds that are used for chain extending and cross-linking, and achieve self-healing functions with those very moieties, then that would be of great importance since no additional external bonds need to be introduced into the polymer networks. 
From this point of view, chemical bonds formed from isocyanate chemistry are highly interesting, since the urethane or urea bonds are mildly formed and widely used to prepare many different kinds of functional polymer materials. However, the dynamic isocyanate chemistry is rarely studied, since the dissociative reversion of, for example, carbamate or urea bonds to isocyanates and hydroxyl or amine groups typically occurs at high temperatures $\left(>200{ }^{\circ} \mathrm{C}\right)$, and is associated with deleterious side reactions..$^{32}$ The dynamic reaction of urethane between isocyanate and hydroxyl groups has indeed been achieved and used for preparing self-healing polymers in the presence of dibutyltin dilaurate (DBTDL), ${ }^{33}$ zinc acetate, ${ }^{34}$ or excess hydroxyl moieties, ${ }^{28}$ by using oxime-based monomers $^{35,36}$ or vinylogous urethane-based vitrimers ${ }^{37}$ at relatively high temperature.

Different from the urethane bond, reversibility is harder to achieve for the urea bond, formed by the reaction between amine and isocyanate groups. Cheng et al. reported that selfhealing polyurea materials ${ }^{38,39}$ can be formed by destabilization of urea using a secondary amine group with large steric hindrance, as this will induce weakening of the urea bond and thus increase the dynamic character of the bond..$^{40}$ However, to the best of our knowledge, dynamic urea bonds formed by primary amine and isocyanate groups have not been reported, and this is primarily attributed to the fast reactions of primary amines and isocyanates that stabilize the reaction products by resonance effects, resulting in highly durable materials. ${ }^{41}$ This seems understandable, since the reaction of primary amine and isocyanate groups is fast, and the formed urea product is regarded as being highly stabilized by resonance effects.

Yet, in the current study we aimed to do precisely this: turning the urea moiety into a dynamic covalent motif. The reason for such a fundamental approach is that if one is able to develop the field of dynamic urea bond formation and selfhealing polyurea materials via dynamic transcarbamoylation processes, it would be feasible to develop entirely novel classes of self-healing polymeric materials. Inspired by the effective catalyzing performance of $\mathrm{Zn}(\mathrm{OAc})_{2}$ on polyurethanes, here we investigated whether we could obtain dynamic covalent urea bonds, formed by primary amines and isocyanate, in the presence of $\mathrm{Zn}(\mathrm{OAc})_{2}$. In other words, we aim to study and thus develop self-healing polymer materials based on the classical covalent urea bond. We studied the reaction kinetics of urea bond formation in the presence and absence of $\mathrm{Zn}(\mathrm{OAc})_{2}$ by nuclear magnetic resonance (NMR), Fourier-transform infrared spectroscopy (FTIR) and gas chromatography-mass spectrometry (GC-MS). The dynamic properties of the urea bond were further confirmed via quantum chemical density-functional theory calculations. Then we set out to unleash the potential of self-healing ureabased polymer materials by preparing two kinds of polydimethylsiloxane- $\mathrm{Zn}(\mathrm{OAc})_{2} \quad$ (PDMS- $\left.\mathrm{Zn}(\mathrm{OAc})_{2}\right)$ cross-linked polymer networks and studied the self-healing properties of these novel materials. Finally, we briefly outline several potential developments based on our findings.

\section{Results and discussion}

\section{Dynamic covalent chemistry of simple urea compounds}

First, we would like to test our hypothesis whether the urea bond can turn into a dynamic covalent bond in the presence of zinc ions at different temperatures (Fig. 1A). To this end, as a proof of principle, we investigated the potentially dynamic properties of the urea bond by studying the dynamics of diethyl urea in the presence of benzylamine and 2-( $p$-tolyl)ethylamine, respectively, and zinc acetate ( $2 \mathrm{wt} \%)$, in DMSO at $90^{\circ} \mathrm{C}$, by GCMS and ${ }^{1} \mathrm{H}$ NMR. We hypothesized that under these conditions either dissociation of the urea bond will produce the original isocyanate, which can then be captured by another amine, or the urea will undergo a Lewis acid-catalyzed nucleophilic addition of an amine onto the urea bond, and exchange one of the original amines.

First of all, indeed the transamination products 1-ethyl-3benzylurea and 1-ethyl-3-(4-methylphenethyl)urea are formed. These products show up in GC-MS after about $1 \mathrm{~h}$ reaction time. In addition, upon continued reaction (typically $24 \mathrm{~h}$ and longer), even the follow-up product [1,3-dibenzyl urea or di(4methylphenethyl)urea] could be observed (Fig. S1†). The asymmetric urea compound can dissociate into two amine and isocyanate compounds. The newly formed benzyl isocyanate and 4-methylphenethyl isocyanate will react with an amine to either re-form or produce 1,3-dibenzyl urea or di(4methylphenethyl)urea compounds. The yield of these formed products depends on the specific reaction conditions. In a control experiment, no transamination products were observed by GC-MS under identical reaction conditions in the absence of $\mathrm{Zn}$ salts, showing that $\mathrm{Zn}(\mathrm{OAc})_{2}$ plays a vital role in the dynamic urea bond formation (Fig. S2 $\uparrow$ ).

In order to further investigate whether the mechanism behind this dynamic character is based on dissociation into the corresponding amine and isocyanate or a catalyst-assisted exchange of amines, FTIR was used to characterize the structural change. A urea-terminated linear PDMS was prepared by reacting amine-terminated polydimethylsiloxane (DMS-A12, $M_{\mathrm{n}}$ $=1000 \mathrm{~g} \mathrm{~mol}^{-1}$ ) with phenethyl isocyanate. This reaction was chosen because the product was a very viscous liquid which can stick onto a $\mathrm{KBr}$ plate for IR measurement. After heating this urea-terminated PDMS in the presence of $5 \mathrm{wt} \% \mathrm{Zn}(\mathrm{OAc})_{2}$ at $90{ }^{\circ} \mathrm{C}$ for $16 \mathrm{~h}$, an obvious isocyanate peak at $2237 \mathrm{~cm}^{-1}$ was detected, which confirmed that some urea bonds were dissociated into the constituent amine and isocyanate groups. After cooling the liquid down to room temperature for $72 \mathrm{~h}$, the FTIR curve almost recovers to the original one (Fig. 1B). These results suggest that the dynamic character of urea bonds is achieved by dissociation into the corresponding amine and isocyanate. During this process the concomitant changes of the amine and urea signals in the IR spectra are not obvious and hard to differentiate because of hydrogen bonding formation and the negligible decomposition of the urea group to amine and isocyanate groups (Fig. S3†).

The dynamic character of the urea bond at elevated temperatures under $\mathrm{Zn}$ ion catalysis was further confirmed by ${ }^{1} \mathrm{H}$ NMR 


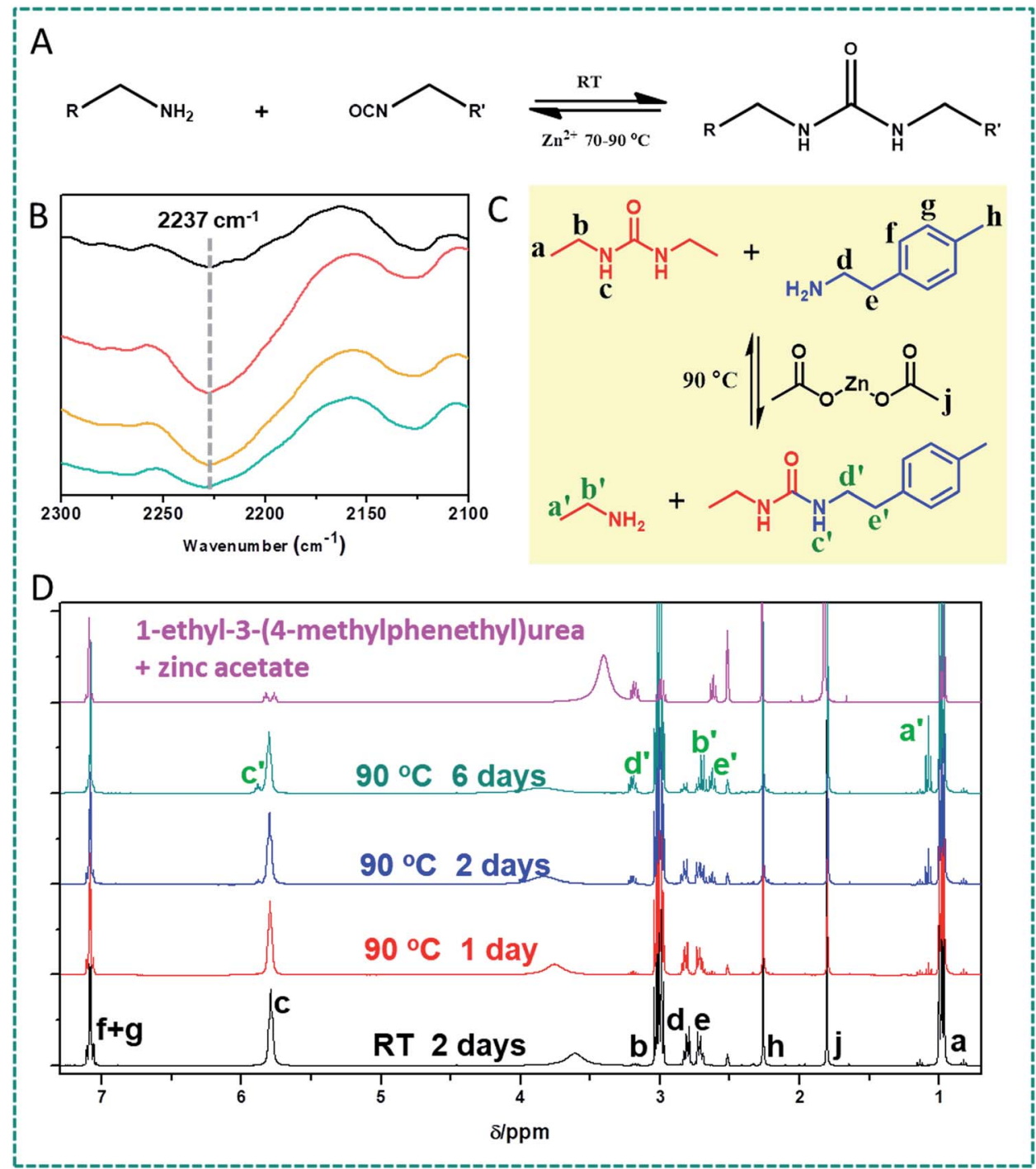

Fig. 1 (A) Fundamental question of this study: can the urea bond be made reversible by Lewis acid catalysis in the presence of zinc ions at different temperatures, and thus open up the way for intrinsically self-healing polyureas? (B) FTIR spectra of a linear PDMS-Zn(OAc) 2 : a freshly prepared sample (black curve, top); the fresh sample was heated at $90{ }^{\circ} \mathrm{C}$ for $16 \mathrm{~h}$ (red curve), and then cooled down to room temperature for $24 \mathrm{~h}$ (yellow curve), and finally kept at room temperature for $72 \mathrm{~h}$ (dark cyan curve, bottom). (C) Reaction between 1,3-diethylurea and 2-( $p$-tolyl) ethylamine in the presence of $\mathrm{Zn}(\mathrm{OAc})_{2}$. (D) ${ }^{1} \mathrm{H}$ NMR spectra of a 1,3-diethylurea, 2 - $\left(p\right.$-tolyl)ethylamine and $\mathrm{Zn}(\mathrm{OAc})_{2}$ mixture $(\mathrm{reaction}$ shown in (C)) reacted in DMSO at room temperature for 2 days (black curve), and at $90{ }^{\circ} \mathrm{C}$ for different time periods (red, blue and dark cyan curves); the pink spectrum (top) is that of a mixture of independently prepared 1-ethyl-3-(4-methylphenethyl)urea and zinc acetate.

studies. We choose 1,3-diethyl urea as a model molecule to study the dynamic properties of urea in the presence of zinc ions. We first conducted the NMR experiment by heating a mixture of 1,3diethyl urea, 2-(p-tolyl)ethylamine and $\mathrm{Zn}(\mathrm{OAc})_{2}$ in DMSO- $\mathrm{d}_{6}$ at $90{ }^{\circ} \mathrm{C}$. If the urea bond would exhibit reversibility, then the reformed ethyl isocyanate will react with 2 -(p-tolyl)ethylamine to form the new compound 1-ethyl-3-(4-methylphenethyl)urea (Fig. 1C). Fig. 1D shows the ${ }^{1} \mathrm{H}$ NMR spectra of the compounds obtained after treatment for different time periods. The new peaks $\mathrm{a}^{\prime}$ and $\mathrm{b}^{\prime}$, and $\mathrm{c}^{\prime}, \mathrm{d}^{\prime}$ and $\mathrm{e}^{\prime}$ belonging to ethylamine and 1ethyl-3-(4-methylphenethyl)urea are confirmed by comparison with the spectrum observed for independently prepared 1-ethyl-3(4-methylphenylethyl)urea. Especially, a new peak $\left(c^{\prime}\right)$ at $5.87 \mathrm{ppm}$ attributed to the newly formed urea bond confirms the formation of 1-ethyl-3-(4-methylphenethyl)urea. Similar NMR results were also observed upon heating a mixture of 1,3-diethyl urea and $\mathrm{Zn}(\mathrm{OAc})_{2}$ in $\mathrm{DMSO}-\mathrm{d}_{6}$ at $90{ }^{\circ} \mathrm{C}$. If the urea bond is reversible under these conditions, then it can be expected that ethylamine and ethyl isocyanate will be formed. Indeed, NMR peaks corresponding to ethylamine were observed (see $\mathrm{a}^{\prime}$ and $\mathrm{b}^{\prime}$ ). No signal for ethyl isocyanate was found, which we attribute to reaction of the isocyanate with the water in the DMSO- $\mathrm{d}_{6}$ (Fig. S4 $\dagger$ ). Fig. S5† shows the NMR spectra of samples with this initial composition when reacted for $16 \mathrm{~h}$ at different temperatures, from which we can see that the peak attributed to the new urea bond appears when the reaction temperature is more than $70{ }^{\circ} \mathrm{C}$. This indicates that the urea bond becomes evidently dynamic at this temperature. 


\section{Quantum chemical calculations}

With these results in hand, we aimed to further delineate the mechanism by B3LYP/6-311+G(d,p) quantum chemical methods (with a Lan2LDZ pseudopotential to model the $\mathrm{Zn}$ cation). To this end, we studied the dissociation of diethyl urea to ethylamine and ethyl isocyanate. All calculations were run with the Gaussian 16 suite of programs, and used the SMD solvent model implemented therein to mimic the effects of DMSO.

The decomposition of diethyl urea (RC) into $\mathrm{CH}_{3}-\mathrm{CH}_{2}-$ $\mathrm{NCO}$ and $\mathrm{CH}_{3}-\mathrm{CH}_{2}-\mathrm{NH}_{2}$ can be described as starting with $\mathrm{C}-\mathrm{N}$ bond lengthening, or as starting with a proton shift, or as a reaction in which both processes take place simultaneously. The $\mathrm{C}-\mathrm{N}$ bond lengthening route does not lead to a viable minimum even if the $\mathrm{C} \cdots \mathrm{N}$ distance is extended to $>4 \AA$, at which point this route was abandoned. When starting this $\mathrm{H}$ transfer, it became quickly clear that upon transfer of a proton from one $\mathrm{N}$ atom to the other, none of the $\mathrm{C}-\mathrm{N}$ bonds changed drastically. In other words, the dissociation reaction takes place sequentially, starting with $\mathrm{H}^{+}$transfer followed by $\mathrm{C}-\mathrm{N}$ cleavage. The reaction profile proceeds through a first transition state (TS1) in which one of the $\mathrm{N}-\mathrm{H}$ bonds of an amide group lengthens and eventually breaks, and the transferred proton forms a $\mathrm{N}-\mathrm{H}$ bond with the $\mathrm{N}$ atom of the other amino group (Fig. 2A: the proton is transferred from $\mathrm{N}_{1}$ to $\mathrm{N}_{2}$ ). In this TS, the $\mathrm{N}_{1}-\mathrm{H}$ bond is elongated to $1.33 \AA$ and the proton starts to bind with the $\mathrm{N}_{2}$ amide atom with a distance of $1.30 \AA$ between them. Because of the $\mathrm{H}^{+}$migration, the electron density in the amide bond changes, leading to slight bond length changes of the $\mathrm{N}_{1}-\mathrm{C}$ and $\mathrm{N}_{2}-\mathrm{C}$ bonds: the $\mathrm{N}_{1}-\mathrm{C}$ bond shortens from 1.38 to $1.33 \AA$, while the $\mathrm{N}_{2}-\mathrm{C}$ bond increases from $1.38 \AA$ to $1.51 \AA$. The (zero-point energy corrected) energy of TS1 is ca. $44 \mathrm{kcal} \mathrm{mol}^{-1}$ higher than that of the urea reactant, clearly in line with the high stability of urea at room temperature, making this the rate-determining step.

Subsequently, a zwitterionic intermediate is formed, in which the $\mathrm{N}_{1}-\mathrm{C}$ and $\mathrm{N}_{2}-\mathrm{C}$ bond distances are 1.29 and $1.57 \AA$, respectively. Starting from diethyl urea as the reactant, the overall reaction to this intermediate is endothermic by $23.3 \mathrm{kcal} \mathrm{mol}^{-1}$. Next, the $\mathrm{N}_{2}-\mathrm{C}$ bond is elongated, reaching 2.18 $\AA$ in the second TS (TS2), while the $\mathrm{N}_{1}-\mathrm{C}$ bond is shortened to $1.24 \AA$ and the $\mathrm{C}=\mathrm{O}$ bond decreases from $1.24 \AA$ (in the initial diethyl urea) to $1.19 \AA$. This second transition state has an energy barrier of only $3.7 \mathrm{kcal} \mathrm{mol}^{-1}$, to yield ethyl isocyanate and ethyl amine as decomposition products (P2) by an exothermic process of $-2.8 \mathrm{kcal} \mathrm{mol}^{-1}$ from the zwitterionic intermediate. The overall decomposition reaction from urea to isocyanate and amine is therefore endothermic by more than $20 \mathrm{kcal} \mathrm{mol}^{-1}$, in line with the high stability of urea-based compounds.

When studying the urea decomposition reaction in the presence of $\mathrm{Zn}$ (II), there are multiple possible pathways, as the $\mathrm{Zn}$ atom can bind to the carbonyl $\mathrm{O}$ atom, or to any of the $\mathrm{N}$ atoms in the amino group, i.e. to the $\mathrm{N}$ atom from which the proton is transferred $\left(\mathrm{N}_{1}\right)$, or to the $\mathrm{N}$ atom to which the proton is transferred $\left(\mathrm{N}_{2}\right)$. In the first pathway (see Fig. 2B), in which the $\mathrm{Zn}$ atom is bound to the carbonyl $\mathrm{O}$ atom, the first TS (TS1) is characterized by a proton transfer energy barrier of just over

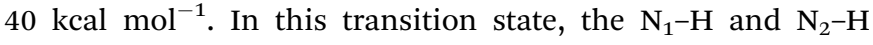
bonds are - analogous to the uncatalyzed route - elongated to $1.33 \AA$ and shortened to $1.30 \AA$, respectively, with the $\mathrm{N}_{1}-\mathrm{C}$ bond shortened from 1.34 to $1.30 \AA$, and the $\mathrm{N}_{2}-\mathrm{C}$ bond increased from $1.35 \AA$ to $1.47 \AA$. The full proton transfer yields the intermediate (P1) with an endothermic energy step of $19.6 \mathrm{kcal} \mathrm{mol}^{-1}$. Therefore, the role of the O-bound $\mathrm{Zn}$ is to reduce the energy of both the TS and the zwitterionic intermediate by ca. 3-4 kcal mol ${ }^{-1}$, suggesting a significant catalytic effect of $\mathrm{Zn}$ cations. This yields an expected rate acceleration at $90{ }^{\circ} \mathrm{C}$ of roughly 2 orders of magnitude, in line with the absence of observed exchange reactions in the absence of $\mathrm{Zn}$ salts. In contrast, the second transition (TS2) state now involves a greatly increased activation energy of $18.8 \mathrm{kcal} \mathrm{mol}^{-1}$. This TS structure is only slightly lower in energy than the first one, suggesting complex and likely condition-dependent kinetics of this reaction, which will finally yield product $\mathrm{P} 2$.

On the other hand, there is an alternative pathway which involves coordination of $\mathrm{Zn}^{2+}$ to the $\mathrm{N}$ atom (the $\mathrm{Zn}-\mathrm{N}_{1}$ distance is $2.16 \AA$ ) from which the proton migrates to the other $\mathrm{N}$ atom $\left(\mathrm{N}_{2}\right)$. In this structure, the $\mathrm{N}_{1}-\mathrm{C}$ distance is somewhat increased (1.38 to $1.45 \AA$ ) while $\mathrm{Zn} \cdots \mathrm{N}$ coordination shortens the $\mathrm{N}_{2}-\mathrm{C}$ bond distance slightly (1.38 to $1.35 \AA$ ) (Fig. S6†). The proton transfer TS - with similar $\mathrm{N} \cdots \mathrm{H}$ distances as before - now has an energy higher than $48 \mathrm{kcal} \mathrm{mol}^{-1}$, i.e. this reaction will be appreciably slower than the uncatalyzed one. Also the following $\mathrm{C}-\mathrm{N}$ lengthening TS has to pass an energy barrier of $20.0 \mathrm{kcal} \mathrm{mol}^{-1}$, but this is evidently not the rate-limiting step. Finally, coordination of $\mathrm{Zn}^{2+}$ to the $\mathrm{N}_{2}$ atom does not lead to a viable reaction progress: the proton transfer TS is at least $55 \mathrm{kcal} \mathrm{mol}^{-1}$ above the reactants, which makes this an uncompetitive route.

We interpret these data as indicating that the decomposition reaction of urea is nearly absent at room temperature, either in the presence or absence of $\mathrm{Zn}^{2+}$ due to significant energy barriers. However, at elevated temperatures, crossing these barriers can become viable, even though the overall reaction (from urea to isocyanate + amine) is endothermic. Here we thus calculate a significant effect of $\mathrm{Zn}^{2+}$ cations, with catalytic rate differences of typically two orders of magnitude. In reality, these kinetics will likely be more complicated, as acid/base catalysis will likely also play a role. In addition, the coordination of $\mathrm{Zn}$ might change during the reaction, and possibly more $\mathrm{Zn}$ ions might be involved. We aim to address these facets in future work, but it suffices to state that quantum chemistry calculations confirm that $\mathrm{Zn}$ ions catalyze the decomposition of urea, and that the overall Zn-catalyzed dissociation process can be viewed as sketched in Fig. 2C.

\section{Self-healing polymers}

Given the wide-ranging use of polyureas for high-stability polymers, and these results obtained for model compounds with dynamic covalent urea bonds, we aimed to develop selfhealing urea-based polymers. Our first strategy to design selfhealing polymer materials based on this zinc ion-catalyzed 


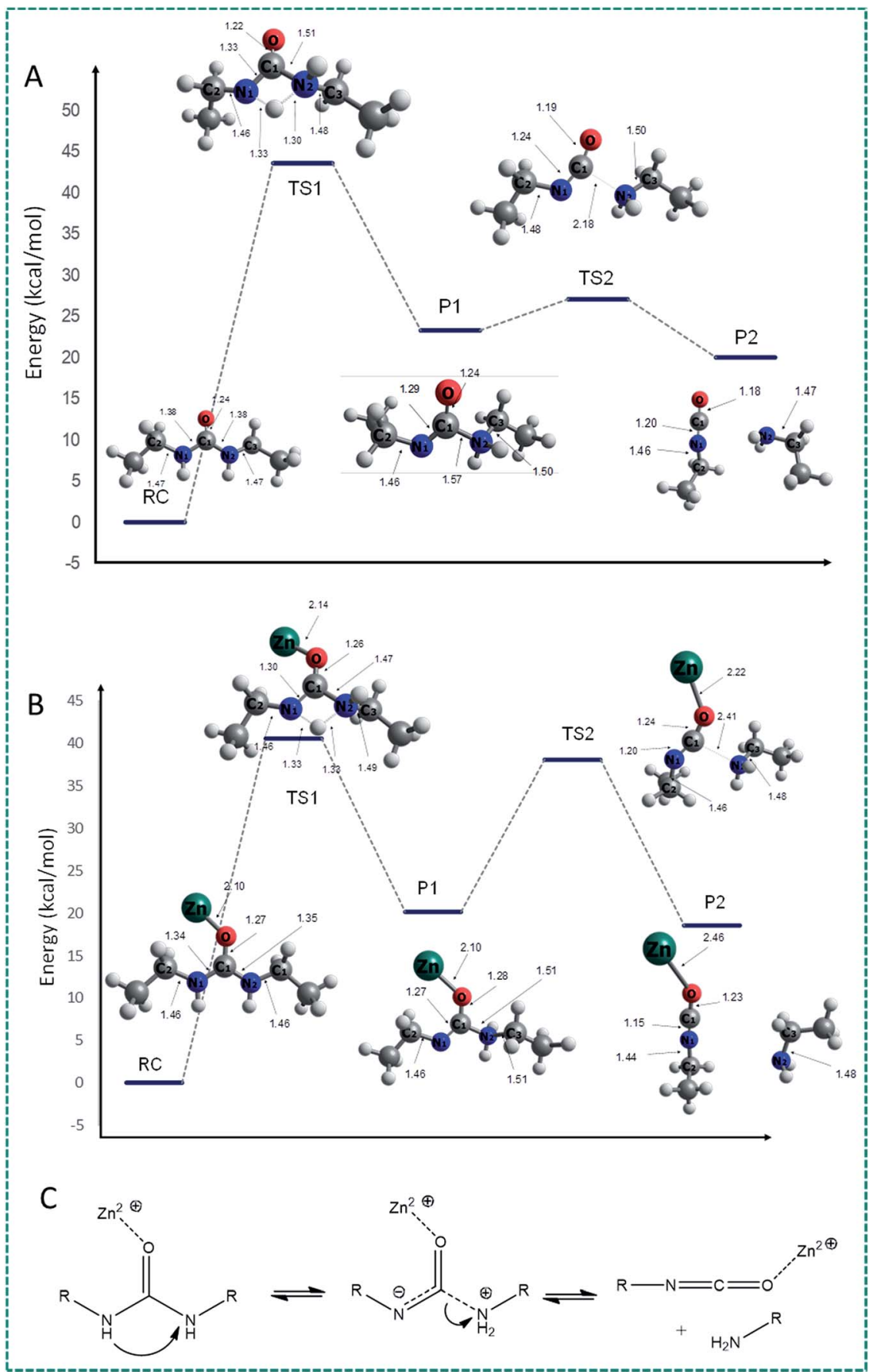

Fig. 2 (A) Energy profile of the decomposition reaction of diethyl urea into ethyl isocyanate and ethyl amine. (B) Energy profile of the Zn(॥) catalyzed-decomposition of diethylurea into ethyl isocyanate and ethyl amine. The $\mathrm{Zn}$ atom is coordinated to the carbonyl $\mathrm{O}$ atom. (C) Schematic illustration of the mechanism of the $\mathrm{Zn}$-catalyzed reversible dissociation and re-formation of ureas.

reversible urea bond is shown in Fig. 3A: a primary amineterminated polydimethylsiloxane (DMS-A21, $M_{\mathrm{n}}=5000 \mathrm{~g}$ mol $^{-1}$, DMS-A15 or DMS-A12) was crosslinked using 1,6-diisocyanate (HDI) and (20-25\% aminopropylmethylsiloxane)dimethylsiloxane copolymer (AMS-1203) with $\mathrm{Zn}(\mathrm{OAc})_{2}$ as a catalyst. The obtained polymer materials (P1-P6, ESI $\dagger$ ) were named PDMS-Zn $(\mathrm{OAc})_{2}-\mathrm{I}$, which was characterized by IR (Fig. S7 $\dagger$ ), and the mechanical properties are summarized in
Table S1. $\dagger$ Upon being subjected to a mechanical scratch, the PDMS-Zn $(\mathrm{OAc})_{2}-\mathrm{I}$ (P1) networks can be repaired by thermal treatment at $90{ }^{\circ} \mathrm{C}$ for $30 \mathrm{~min}$ (Fig. 3B and C). The self-healing properties of the PDMS-Zn(OAc) $)_{2}$-I (P1) network were further verified by tensile strength experiments. The materials were first cut into two pieces, and then put together followed by heating the polymer at $90{ }^{\circ} \mathrm{C}$ for $24 \mathrm{~h}$. Remarkably, the stress strength and the maximum elongation before breaking (elongation at 


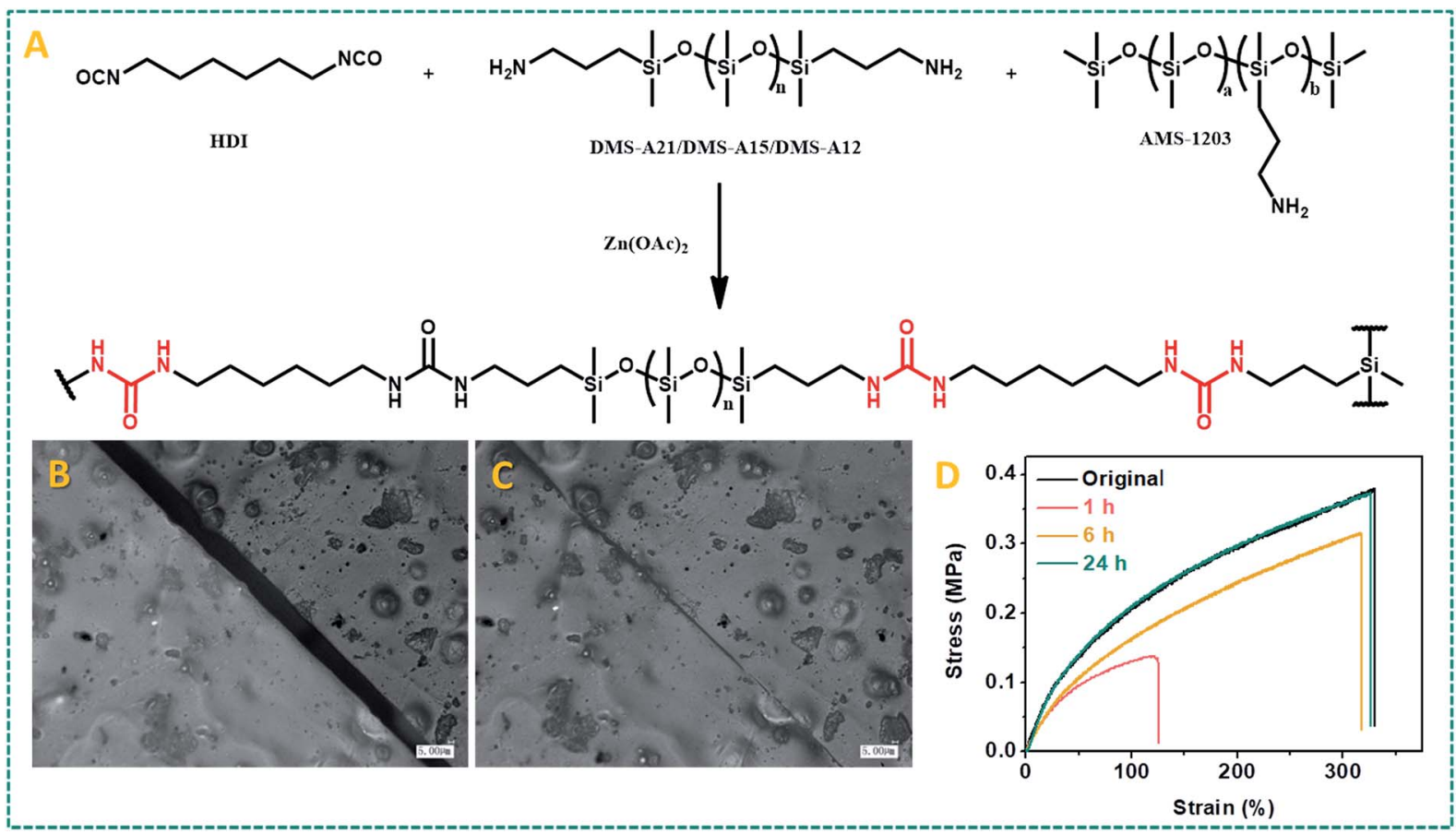

Fig. 3 (A) Schematic representation of the synthetic route of the PDMS-Zn(OAc) $)_{2}-1$ network. (B) Optical image of the as-prepared PDMS$\mathrm{Zn}(\mathrm{OAc})_{2}-\mathrm{I}$ film (P1) with a scratch (scar bar: $5 \mu \mathrm{m}$ ). (C) Optical image of the damaged PDMS $-\mathrm{Zn}(\mathrm{OAc})_{2}-\mathrm{I}$ film after thermal treatment at $90{ }^{\circ} \mathrm{C}$ for $30 \mathrm{~min}$ (scar bar: $5 \mu \mathrm{m}$ ). (D) Stress-strain curves of the original PDMS-Zn(OAc) ${ }_{2}-\mathrm{I}$ (P1) films and the cut-off films after thermal treatment at $90{ }^{\circ} \mathrm{C}$ for different time periods.

break point) of this cut-off sample both fully recovered to the original value (Fig. 3D), which indicates that the as-prepared PDMS- $\mathrm{Zn}(\mathrm{OAc})_{2}-\mathrm{I}$ films possess excellent self-healing properties. The degree of elongation before breaking of the PDMS$\mathrm{Zn}(\mathrm{OAc})_{2}$ networks decreases with increasing the cross-linker AMS-1203 content due to the enhanced cross-linking density, but all of these three PDMS- $\mathrm{Zn}(\mathrm{OAc})_{2}$ samples displayed excellent self-healing properties, with a healing efficiency of more than $90 \%$ as deduced from both tensile stress and elongation before breaking experiments (Table S1, $\uparrow$ P2-P4). Upon decreasing the molecular weight of amine-terminated polydimethylsiloxane from 5000 to 3000 (Table S1, $\dagger$ P5), the elongation at break and tensile strength decreased, again due to the effectively enhanced cross-linking density. However, this polymer still showed a healing efficiency of $93 \%$. Further decreasing the molecular weight of amine-terminated polydimethylsiloxane to 1000 (Table S1, $\dagger$ P6) makes the self-healing properties disappear, because the roughness of the cut-off sample prevents the two parts from being placed intimately together. In order to outline the role of zinc ions in the selfhealing process, several control experiments were conducted. First of all, we tested the self-healing behavior of the several PDMS films with different catalysts (Fig. 4A). In the absence of zinc ions, the tensile stress only recovers to $45 \%$. In the presence of $\mathrm{Zn}(\mathrm{OAc})_{2}$ and $\mathrm{Zn}\left(\mathrm{CF}_{3} \mathrm{SO}_{3}\right)_{2}$, PDMS networks exhibit excellent self-healing properties. However, in the presence of magnesium acetate no self-healing was observed. Therefore the nature of the metal ion is crucial. All of the above results demonstrate that the zinc ion plays a very important role during the self-healing process, rather than the anion, which does not seem to be catalytically critical. We also examined the selfhealing behavior at room temperature in the presence of $\mathrm{Zn}(\mathrm{OAc})_{2}$; no self-repairing was observed, indicating that the self-healing process is a thermally activated process, in line with the computations. Finally, we studied the influence of zinc concentration on the self-healing behavior of the PDMS$\mathrm{Zn}(\mathrm{OAc})_{2}$. A clearly increased self-healing is observed with an increased $\mathrm{Zn}$ concentration, up to a saturation limit: when the zinc concentration is more than $0.5 \mathrm{wt} \%$, we achieve more than $90 \%$ healing efficiency, while further increasing the $\mathrm{Zn}$ concentration to $>1 \mathrm{wt} \%$ does not seem to add any further benefits (Fig. 4B). We propose that the self-healing properties of the PDMS- $\mathrm{Zn}(\mathrm{OAc})_{2}$ - under these conditions - can be attributed to the dynamic nature of urea bonds catalyzed by zinc ions, which is schematically shown in Fig. 4C.

Many self-healing PDMS materials relying on dynamic covalent or non-covalent bonds have been developed. The main challenge in this field is to achieve repairable PDMS materials with high mechanical strength. Such strong and repairable materials may be achieved by varying the monomer composition and molecular weight, using a cross-linking network structure and/or introducing supramolecular interactions. To realize this goal, another kind of PDMS-Zn(OAc) $)_{2}$-II (P7: PDMSIPDI-triHDI-Zn $(\mathrm{OAc})_{2}$, a detailed preparation procedure can be found in the ESI + ) material was prepared by reacting a DMS-A12 (primary amine-terminated polydimethylsiloxane, $M_{\mathrm{n}}=1000 \mathrm{~g}$ $\mathrm{mol}^{-1}$ ) monomer with isophorone diisocyanate (IPDI), followed by cross-linking with a tri-functional homopolymer of 


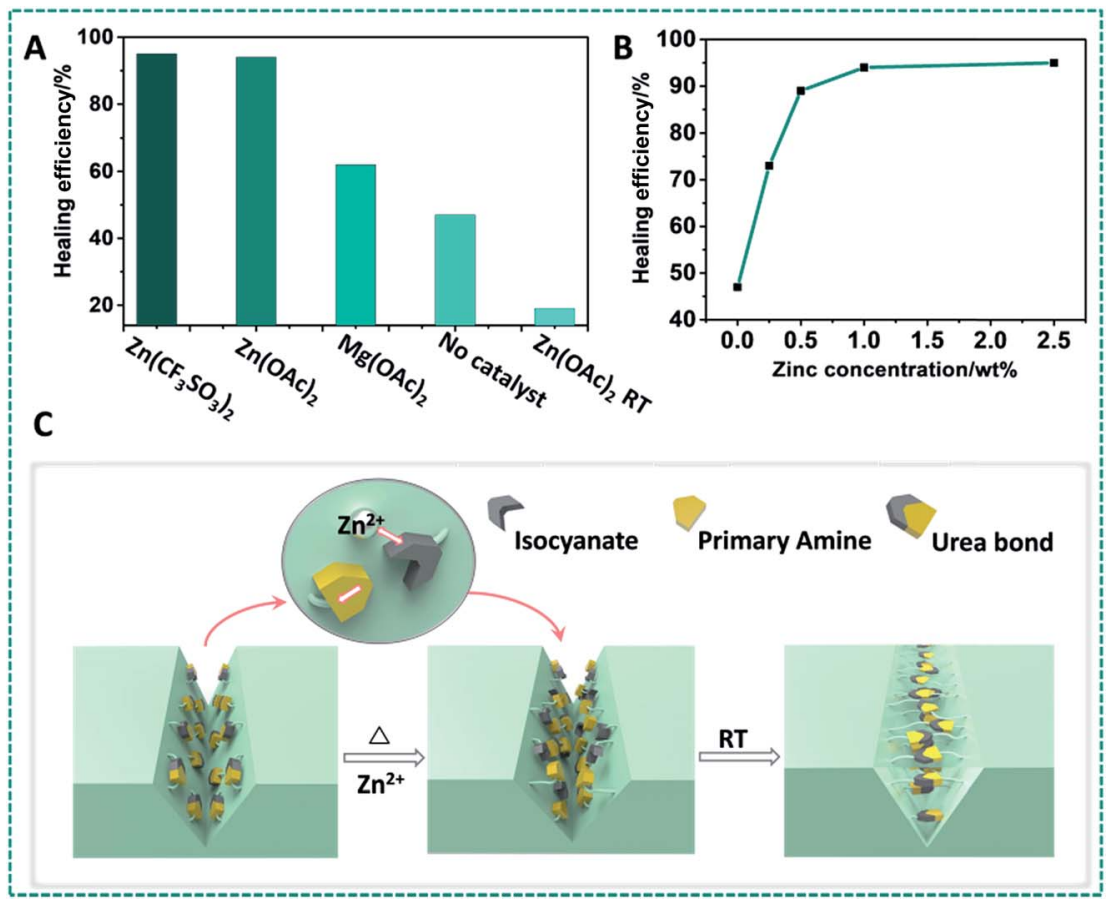

Fig. 4 (A) Healing efficiency of PDMS materials with different catalysts at $90^{\circ} \mathrm{C}$. (B) Healing efficiency of the PDMS-Zn(OAc) $2_{2}-\mathrm{I}$ network (P4) as a function of $\mathrm{Zn}(\mathrm{OAc})_{2}$ concentration. (C) Schematic illustration of the self-healing process of the PDMS-Zn(OAc) 2 networks: in the presence of $\mathrm{Zn}$ ions, urea moieties can open up and subsequently restore the materials by re-forming in novel geometries.

hexamethylene diisocyanate (tri-HDI) (Fig. 5A). In this system, the hydrogen bonding density was raised by decreasing the molecular weight of the siloxane homopolymer, resulting in an obvious increase of the mechanical strength. In addition, the degree of crystallinity was reduced by replacing HDI with IPDI as the chain extender, which will increase the elastic properties of the materials. The result of these changes is that these selfhealing urea-linked PDMS-Zn(OAc) $)_{2}$-II materials had a high tensile stress (7.0 MPa) and elongation at break (more than $600 \%$ ), much higher than those of P2-P5 (Table S1†). Due to the catalyzing role of zinc ions, this material still showed excellent self-healing properties as shown in Fig. 5B and C. Two PDMS$\mathrm{Zn}(\mathrm{OAc})_{2}$-II $(\mathrm{P} 7)$ films with different widths $(1 \mathrm{~cm}$ and $0.6 \mathrm{~cm})$ were cut into two pieces, and two of them (one is $1 \mathrm{~cm}$, the other is $0.6 \mathrm{~cm}$ ) were put together and then heated at $110^{\circ} \mathrm{C}$ for $16 \mathrm{~h}$, the healed samples can hold a weight of at least $500 \mathrm{~g}$ (Fig. 5B). Tensile experiment results also demonstrated that both the tensile stress and elongation at break can recover to about $90 \%$ after healing at $110{ }^{\circ} \mathrm{C}$ for $16 \mathrm{~h}$ (Fig. 5C). We summarized the mechanical properties of reported self-healing PDMS materials and the results are presented in Fig. 5D. We can see that most of the as-developed self-healing PDMS materials possess weak mechanical strength. Only one example reported had a mechanical strength 9.46 MPa higher than our PDMS materials, but that material displayed a low elongation at break..$^{52}$ This comparison illustrates that our self-healing PDMS materials not only display excellent healing efficiency, but also possess superior mechanical properties. In this particular system, $110{ }^{\circ} \mathrm{C}$ was used to achieve the self-healing, resulting from the presence of many hydrogen bonds. Extensive $\mathrm{H}$ - bonding results in frozen segments at lower temperatures, and effects that repair can only take place upon sufficient heating to break the hydrogen bonds, so as to allow polymer segments to be able to move. This elevated temperature is not essential for Zn-catalyzed repair of polyureas. To demonstrate that the Zn-catalyzed self-healing of polyureas also takes place at much lower temperatures, we changed the PDMS monomer from DMS-A12 to DMS-A21 (molecular weight is changed from 1000 to 5000) and prepared another kind of PDMS-Zn(OAc) $)_{2}-\mathrm{II}$ (P8; see the ESI $\dagger$ for details of the preparation). This polymer is much softer than P7 due to the reduced hydrogen bonding, and displays a relatively low degree of cross-linking. As Fig. $\mathrm{S} \dagger \dagger$ shows, this material can be repaired at $70{ }^{\circ} \mathrm{C}$ within $30 \mathrm{~min}$, with more than $90 \%$ recovery of both the tensile stress and elongation at break. In other words, the repair is smooth even upon gentle heating.

In order to study the influence of the zinc salt on the thermal stability of these materials, we conducted thermogravimetric analysis (TGA) experiments of PDMS- $\mathrm{Zn}(\mathrm{OAc})_{2}$-II with different concentrations of $\mathrm{Zn}(\mathrm{OAc})_{2}$, and the results are shown in Fig. S9. $\dagger$ All of these materials exhibit relatively good thermal stability up to $250{ }^{\circ} \mathrm{C}$. The PDMS-Zn(OAc) $)_{2}$-II with concentrations of $1 \mathrm{wt} \%$ and $2 \mathrm{wt} \%$ start to decompose at around $255^{\circ} \mathrm{C}$, while this degradation behavior happens at around $280^{\circ} \mathrm{C}$ for PDMS- $\mathrm{Zn}(\mathrm{OAc})_{2}$-II without zinc. This means that addition of the zinc salt at these concentrations will reduce the thermal stability of the materials only slightly.

In addition, in order to study the influence of the zinc salt on the microscopic structure of materials, ultrathin films of PDMS-Zn $(\mathrm{OAc})_{2}-\mathrm{II}$ (P7) were examined by transmission 


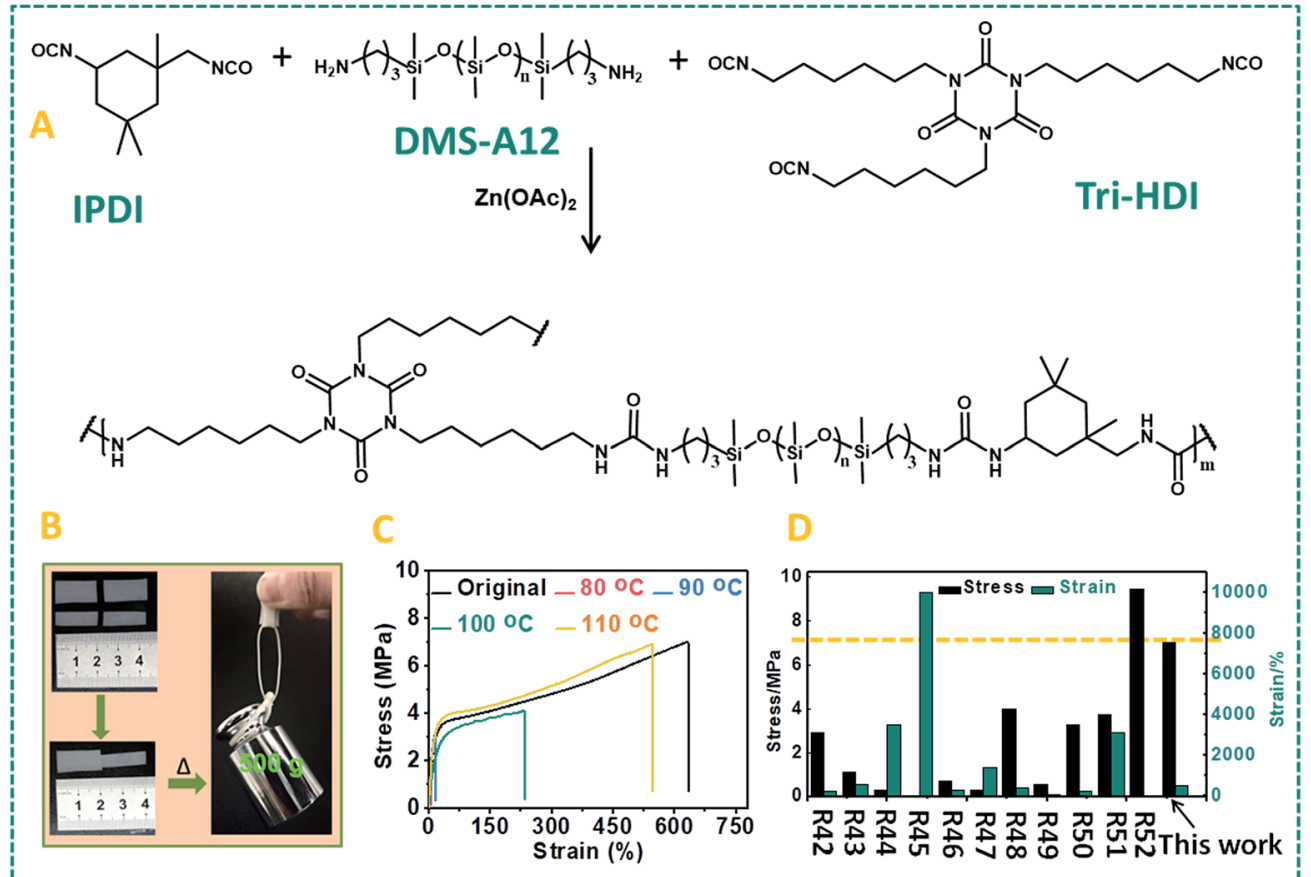

Fig. 5 (A) Schematic representation of the synthetic route of the PDMS-Zn(OAc) ${ }_{2}-I I(P 6)$ network. (B) Picture showing the cut-off and healed PDMS-Zn(OAc) $)_{2}-I I(P 7)$ films, and the ability of even thin repaired pieces to hold $0.5 \mathrm{~kg}$. (C) Stress-strain curves of the original PDMS-Zn(OAc) ${ }_{2}-I I$ (P7) films and the self-healed films after thermal treatment at different temperatures. (D) Comparison of our PDMS-Zn(OAC) $2-1 /$ (P7) materials with previously reported self-healing PDMS in the literature ${ }^{42-52}$ in terms of breaking strength and elongation at break.

electron microscopy (TEM). The results showed that no microphase separation was observed for the polymer networks, but only aggregates formed with zinc salts were found (Fig. S10†), which we tentatively attribute to the low solubility of $\mathrm{Zn}(\mathrm{OAc})_{2}$ in tetrahydrofuran. Although there are some (catalytically likely non-active) aggregates at these higher wt\%, overall, zinc ions can still catalyze the dynamic chemistry of urea bonds effectively, as also indicated by the observation that only $0.5 \mathrm{wt} \%$ zinc catalyst is needed to obtain excellent healing efficiency.

\section{Mechanism of self-healing in polyurea polymers}

In order to verify the proposed self-healing mechanism and dynamic properties of the urea bond, we first tested the solubility of the cross-linked PDMS- $\mathrm{Zn}(\mathrm{OAc})_{2}$ materials $(\mathrm{P} 4)$ in toluene. As shown in Fig. 6A, the PDMS- $\mathrm{Zn}(\mathrm{OAc})_{2}$ materials can be dissolved in toluene within $4 \mathrm{~h}$ by heating at $90{ }^{\circ} \mathrm{C}$, while only swelling behavior (Fig. 6B) was observed after immersion in toluene at room temperature for $24 \mathrm{~h}$, and also upon immersion at $90{ }^{\circ} \mathrm{C}$ for $24 \mathrm{~h}$ without the zinc catalyst (Fig. 6C). In the absence of reversible dynamic bonds, it is expected that materials can only be swelled by solvent, but cannot be dissolved. This experiment shows the dynamic character of the urea bond upon heating with $\mathrm{Zn}$ salts, and the absence of dynamicity when either zinc or an elevated temperature is absent.

Secondly, a linear PDMS was synthesized by reacting IPDI with amine-terminated polydimethylsiloxane (DMS-A12, $M_{\mathrm{n}}=$ $\left.1000 \mathrm{~g} \mathrm{~mol}^{-1}\right)$ in the presence of $2.5 \mathrm{wt} \% \mathrm{Zn}(\mathrm{OAc})_{2}$. This system was chosen because of the better solution of the forming polymer in THF for further gel permeation chromatography (GPC) measurements. The fully finished reaction between DMSA12 and IPDI formed a linear polyurea with a $M_{\mathrm{n}}$ of $12.3 \times 10^{3} \mathrm{~g}$ $\mathrm{mol}^{-1}$ as analyzed by GPC. The addition of another equivalent of DMS-A12 resulted in degradation of the molecular weight to $4.5 \times 10^{3} \mathrm{~g} \mathrm{~mol}^{-1}$ after $12 \mathrm{~h}$ of incubation at $90{ }^{\circ} \mathrm{C}$ in the presence of $\mathrm{Zn}(\mathrm{OAc})_{2}$. Surprisingly, addition of another equivalent of IPDI led to the recovery of the molecular weight to 12.3 $\times 10^{3} \mathrm{~g} \mathrm{~mol}^{-1}$ again (Fig. 6D). These results demonstrate that the urea bonds are dissociated into isocyanate and amine groups after heat treatment with the help of zinc ions, and can re-form into the urea bond upon cooling.

The dynamic properties of the PDMS- $\mathrm{Zn}(\mathrm{OAc})_{2}$ materials were further investigated by tensile stress relaxation analysis (Fig. 6E). The modulus dropped sharply within the initial tens of seconds, mainly due to the dissociation of hydrogen bonds, disentanglement of the polymer chains and molecular relaxation, and then decreased gradually because of the thermal dynamic exchange of the urea bonds in the networks. Relaxation activation energy $\left(E_{\mathrm{a}, \mathrm{r}}=52 \mathrm{kcal} \mathrm{mol}^{-1}\right)$ was calculated from the slope of the fitting line of the relaxation times according to the Arrhenius equation, shown in the inset diagram of Fig. 6E. Such relatively low relaxation activation energy imparts excellent healing properties to the materials.

From dynamic thermomechanical analysis (DMA) data we can see that compared with the pure PDMS film the modulus of the PDMS- $\mathrm{Zn}(\mathrm{OAc})_{2}$-I (P4) films drops sharply at $\sim 90{ }^{\circ} \mathrm{C}$ (Fig. S11†), indicating a thermal transition here. This result cannot confirm the dynamic mechanism at a molecular level, 


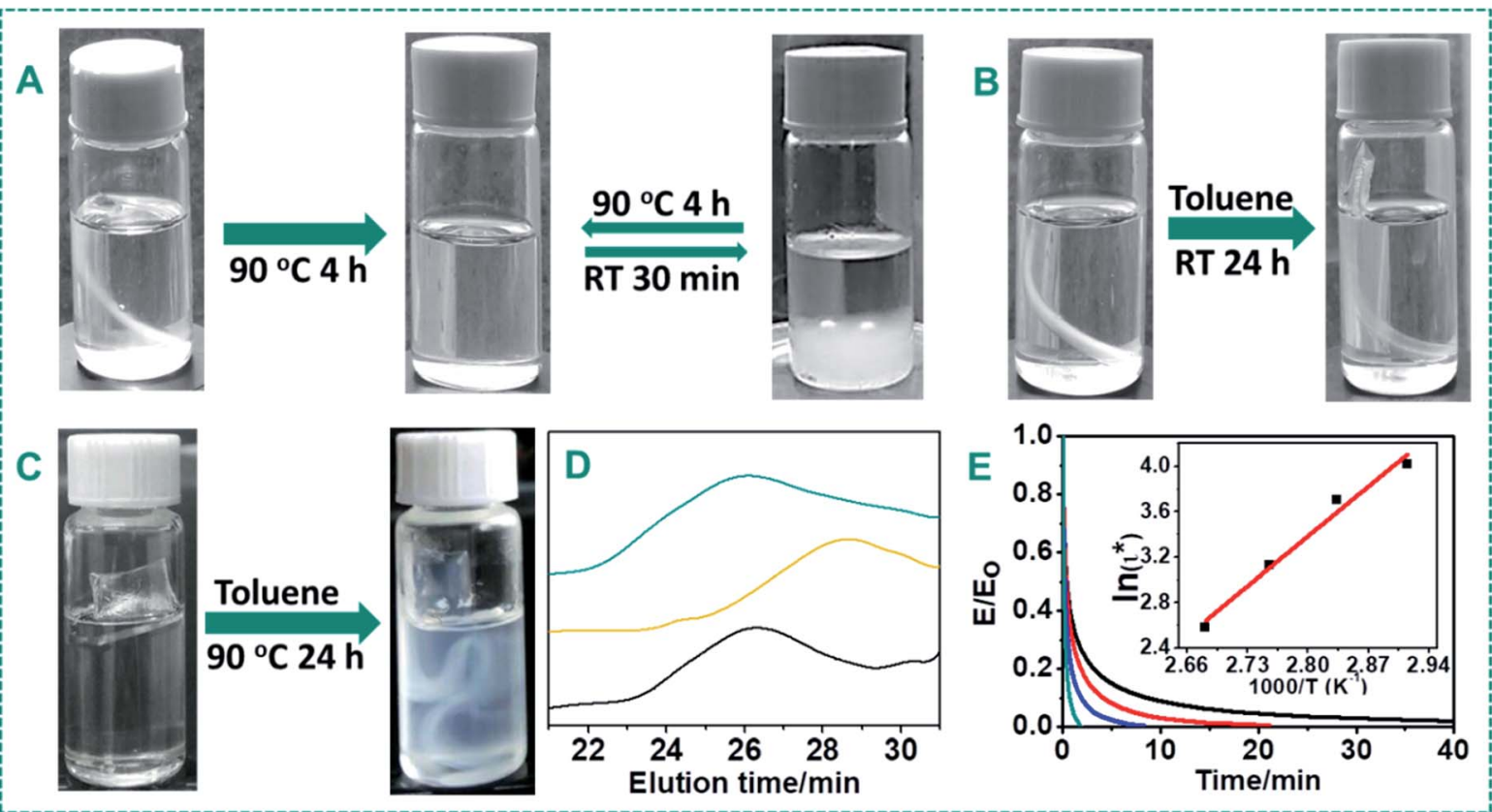

Fig. 6 (A) A PDMS-Zn(OAc) $2_{2}-I$ film (P4) immersed into toluene at $90^{\circ} \mathrm{C}$ for $4 \mathrm{~h}$ and then cooled down to r.t. for 30 min. (B) Freshly prepared PDMS-Zn(OAC) ${ }_{2}-I$ (P4) films immersed into toluene at r.t. for $24 \mathrm{~h}$. (C) Freshly prepared PDMS films (no zinc) immersed into toluene at $90{ }^{\circ} \mathrm{C}$ for 24 h. (D) GPC curve of a linear PU-PDMS. Black curve: a linear PDMS-Zn(OAc) $)_{2}$ formed by IPDI and DMS-A12 with a 1 : 1 ratio; yellow curve: the linear PDMS- $\mathrm{Zn}(\mathrm{OAc})_{2}$ was dissolved in toluene and then 1 equivalent DMS-A12 and $2.5 \mathrm{wt} \% \mathrm{Zn}(\mathrm{OAc})_{2}$ were added and the resulting mixture incubated at $90^{\circ} \mathrm{C}$ for $12 \mathrm{~h}$; dark cyan curve: another equivalent IPDI was added into the solution and stirred for 20 min, and then the solvent was evaporated at r.t. for $12 \mathrm{~h}$. (E) Normalized stress-relaxation curves of PDMS-Zn(OAc) - -II (P7) at various temperatures (black: $70{ }^{\circ} \mathrm{C}$, red: $80{ }^{\circ} \mathrm{C}$, blue: $90^{\circ} \mathrm{C}$, dark cyan: $100^{\circ} \mathrm{C}$ ). Inset: fitting line of the relaxation times according to the Arrhenius equation, and the relaxation activation energy obtained from the slope.

but considering the GPC and solubility experiment results, we believe that this transition comes from the dissociation of the urea bond into isocyanate and amine groups. In this case the cross-linked polymer network is open to some extent, which reduces the cross-linking density. The result of this is that we can see a sharp decrease in the storage modulus of the PDMS$\mathrm{Zn}(\mathrm{OAc})_{2}$ film. In addition, due to the sharp decrease in the degree of cross-linking, the PDMS-Zn(OAc $)_{2}$ film becomes too soft to be stretched, which hampers obtaining modulus data when that temperature is higher than the dynamic temperature. All of the results from GPC, solubility experiments and DMA confirmed that the self-healing mechanism is based on the dissociation of the urea bond at elevated temperatures in the presence of zinc ions, and that the newly formed isocyanate and amine groups will re-form into a urea bond after cooling down to room temperature.

\section{Conclusions}

Despite the high resonance-induced stability of urea moieties, we show here for the first time the dynamic character of ureas in the presence of zinc ions via well-controlled dissociation and exchange experiments and via quantum chemical calculations of small-molecule model urea compounds. We estimate that the presence of zinc ions as a catalyst speeds up the dissociation of ureas by roughly two orders of magnitude, via the formation of
O-bound Zn complexes. Relying on this dynamic urea bond, we developed self-healing $\mathrm{Zn}(\mathrm{OAc})_{2}$-containing polymeric materials that, upon mechanical scratching, can be fully repaired via a simple thermal treatment. Due to the wide range of commercially available primary amines and isocyanate monomers, this method can be used to prepare many kinds of novel self-healing and reprocessable polyurea materials. As a result, dynamic polyurea materials are expected to have significant potential in a range of applications, such as coatings, paints, and 3D printing. ${ }^{53,54}$ Studies on the influence of different catalysts on the dynamic character of urea bonds are currently ongoing in our labs.

\section{Experimental section}

\section{Materials}

Amine-terminated polysiloxane (DMS-A12: $M_{\mathrm{n}}=900-1000 \mathrm{~g}$ mol $^{-1}$, DMS-A15: $M_{\mathrm{n}}=3000 \mathrm{~g}$ mol; DMS-A21: $M_{\mathrm{n}}=5000 \mathrm{~g}$ $\left.\mathrm{mol}^{-1}\right)$ and (20-25\% aminopropylmethylsiloxane)dimethylsiloxane copolymer (AMS-1203: $M_{\mathrm{n}}=25000 \mathrm{~g} \mathrm{~mol}^{-1}$ ) were purchased from Gelest Inc. 1,6-Diisocyanate (HDI), isophorone diisocyanate (IPDI), HDI trimer, phenethyl isocyanate, zinc acetate, magnesium acetate, zinc trifluoromethanesulfonate, 2-( $p$-tolyl)ethylamine, $N, N^{\prime}$-diethylurea and anhydrous tetrahydrofuran were obtained from the best reagent companies. 


\section{Experimental methods}

Preparation of PDMS- $\mathrm{Zn}(\mathrm{OAc})_{2}$ materials. $\mathrm{Zn}(\mathrm{OAc})_{2}$ was dissolved in anhydrous tetrahydrofuran at room temperature, and the amine-terminated PDMS monomer and cross-linker were added into the solution and stirred for $1 \mathrm{~min}$. Then HDI was added into the above solution, the mixture was stirred at room temperature for $5 \mathrm{~min}$, and then it was poured into a PTFE mold. The THF was evaporated at room temperature for $16 \mathrm{~h}$, and subsequently at $40{ }^{\circ} \mathrm{C}$ in a vacuum for $24 \mathrm{~h}$. More details about the preparation process can be found in the ESI. $\dagger$

\section{Characterization}

The weight-average molecular weight of the synthesized PUPDMS was determined by gel permeation chromatography (GPC; HLC-8320) with THF as an eluent phase and PMMA as a standard sample. PDMS-PUR-Zn(OAc $)_{2}$ was characterized by IR spectroscopy on a Fourier transform infrared spectrometer (FTIR; Nicolet 560) in the frequency range of $400-4000 \mathrm{~cm}^{-1}$, and further analyzed by ${ }^{1} \mathrm{H}$ NMR (Bruker ARX-400 at $400 \mathrm{MHz}$ ). Dynamic Mechanical Thermal Analysis (DMTA) experiments were performed using a TA Instruments Q800 machine in the dual cantilever mode. The test temperatures ranged from -30 to $150{ }^{\circ} \mathrm{C}$ and the heating rate was $3{ }^{\circ} \mathrm{C} \mathrm{min}^{-1}$. The strain amplitude used was $50 \mu \mathrm{m}$, and the stretching frequency was $1 \mathrm{~Hz}$. Mechanical tensile-stress experiments were conducted on an Instron 5567 machine (USA) at room temperature with a strain rate of $50 \mathrm{~mm} \mathrm{~min} \mathrm{~m}^{-1}$. The dimension of specimens was $35 \times 8 \times 0.7 \mathrm{~mm}^{3}$. At least four samples of each loading fraction were tested. GC and GC-MS analyses were performed by taking $50 \mu \mathrm{L}$ aliquots of the reaction studied in DMSO- $\mathrm{d}_{6}$ and injecting them in a vial filled with $500 \mu \mathrm{L}$ water and $500 \mu \mathrm{L}$ 1,2-dichloroethane. The sample was gently mixed by shaking, and injections into the GC and GC-MS were from the 1,2-dichloroethane layer. Thermogravimetric analysis (TGA) experiments were performed on a NETZSCH TG 209 instrument at a linear heating rate of $10{ }^{\circ} \mathrm{C} \min ^{-1}$ from 30 to $800{ }^{\circ} \mathrm{C}$ under a nitrogen atmosphere. TEM measurements were conducted with a Tecnai G2 F20 S-TWIN transmission electron microscope (FEI).

\section{Computational methods}

The geometries of all the reactants, products and transition states (TS) were optimized at the B3LYP/6-311+G(d,p) level of theory. Frequency analysis was carried out on all stationary points to confirm their nature (minimum, TS) on the potential energy surface. The universal solvation model SMD was used to mimic the solvent dimethyl sulfoxide (DMSO) for the calculation of the free energy of solvation. All calculations were carried out with the Gaussian16 software package, and Gaussview 6.0 was used as visualization software.

\section{Conflicts of interest}

There are no conflicts to declare.

\section{Acknowledgements}

This work was financially supported by the National Key R\&D Program of China (2017YFE0111500), the National Natural Science Foundation of China (51703143), the EU Horizon 2020 research and innovation programme (No. 734164), the Young Talent Team Science and Technology Innovation Project of Sichuan Province (2016TD0010), and a grant from the State Key Laboratory of Polymer Materials Engineering of Sichuan University (Grant No. sklpme2017-3-04).

\section{Notes and references}

1 N. Kuhl, S. Bode, M. D. Hager and U. S. Schubert, in SelfHealing Materials, ed. M. D. Hager, S. VanDerZwaag and U. S. Schubert, Springer-Verlag Berlin, Berlin, 2016, vol. 273, pp. 1-58.

2 B. Ghosh and M. W. Urban, Science, 2009, 323, 1458-1460.

3 Y. Yang and M. W. Urban, Angew. Chem., Int. Ed., 2014, 53, 12142-12147.

4 F. Herbst, D. Dohler, P. Michael and W. H. Binder, Macromol. Rapid Commun., 2013, 34, 203-220.

5 C. E. Diesendruck, N. R. Sottos, J. S. Moore and S. R. White, Angew. Chem., Int. Ed., 2015, 54, 10428-10447.

6 J. F. Patrick, M. J. Robb, N. R. Sottos, J. S. Moore and S. R. White, Nature, 2016, 540, 363-370.

7 S. R. White, N. R. Sottos, P. H. Geubelle, J. S. Moore, M. R. Kessler, S. R. Sriram, E. N. Brown and S. Viswanathan, Nature, 2001, 409, 794-797.

8 Y. Heo and H. A. Sodano, Adv. Funct. Mater., 2014, 24, 52615268.

9 X. F. Luo and P. T. Mather, ACS Macro Lett., 2013, 2, 152-156.

10 D. Habault, H. J. Zhang and Y. Zhao, Chem. Soc. Rev., 2013, 42, 7244-7256.

11 Y. H. Kim and R. P. Wool, Macromolecules, 1983, 16, 11151120.

12 M. W. Urban, D. Davydovich, Y. Yang, T. Demir, Y. Z. Zhang and L. Casabianca, Science, 2018, 362, 220-225.

13 Y. Yang, D. Davydovich, C. C. Hornat, X. L. Liu and M. W. Urban, Chem, 2018, 4, 1928-1936.

14 W. K. Zou, J. T. Dong, Y. W. Luo, Q. Zhao and T. Xie, Adv. Mater., 2017, 29, 18.

15 F. Garcia and M. M. J. Smulders, J. Polym. Sci., Part A: Polym. Chem., 2016, 54, 3551-3577.

16 R. J. Wojtecki, M. A. Meador and S. J. Rowan, Nat. Mater., 2011, 10, 14-27.

17 C. J. Kloxin and C. N. Bowman, Chem. Soc. Rev., 2013, 42, 7161-7173.

18 C. N. Bowman and C. J. Kloxin, Angew. Chem., Int. Ed., 2012, 51, 4272-4274.

19 H. Otsuka, K. Aotani, Y. Higaki and A. Takahara, J. Am. Chem. Soc., 2003, 125, 4064-4065.

20 S. Yu, R. C. Zhang, Q. Wu, T. H. Chen and P. C. Sun, Adv. Mater., 2013, 25, 4912-4917.

21 X. L. Lu, G. X. Fei, H. S. Xia and Y. Zhao, J. Mater. Chem. A, 2014, 2, 16051-16060. 
22 Y. Amamoto, H. Otsuka, A. Takahara and K. Matyjaszewski, Adv. Mater., 2012, 24, 3975-3980.

23 M. Hernandez, A. M. Grande, W. Dierkes, J. Bijleveld, S. van der Zwaag and S. J. Garcia, ACS Sustainable Chem. Eng., 2016, 4, 5776-5784.

24 S. B. Ji, W. Cao, Y. Yu and H. P. Xu, Adv. Mater., 2015, 27, 7740-7745.

25 S. M. Kim, H. Jeon, S. H. Shin, S. A. Park, J. Jegal, S. Y. Hwang, D. X. Oh and J. Park, Adv. Mater., 2018, 30, 1705145.

26 A. Rekondo, R. Martin, A. R. de Luzuriaga, G. Cabanero, H. J. Grande and I. Odriozola, Mater. Horiz., 2014, 1, 237240.

27 Z. Q. Lei, H. P. Xiang, Y. J. Yuan, M. Z. Rong and M. Q. Zhang, Chem. Mater., 2014, 26, 2038-2046.

28 D. J. Fortman, J. P. Brutman, C. J. Cramer, M. A. Hillmyer and W. R. Dichtel, J. Am. Chem. Soc., 2015, 137, 14019-14022.

29 K. Imato, M. Nishihara, T. Kanehara, Y. Amamoto, A. Takahara and H. Otsuka, Angew. Chem., Int. Ed., 2012, 51, 1138-1142.

30 S. J. Rowan, S. J. Cantrill, G. R. L. Cousins, J. K. M. Sanders and J. F. Stoddart, Angew. Chem., Int. Ed., 2002, 41, 898-952.

31 Y. H. Jin, C. Yu, R. J. Denman and W. Zhang, Chem. Soc. Rev., 2013, 42, 6634-6654.

32 E. Delebecq, J. P. Pascault, B. Boutevin and F. Ganachaud, Chem. Rev., 2013, 113, 80-118.

33 N. Zheng, Z. Z. Fang, W. K. Zou, Q. Zhao and T. Xie, Angew. Chem., Int. Ed., 2016, 55, 11421-11425.

34 Y. Yang and M. W. Urban, Polym. Chem., 2017, 8, 303-309.

35 W. X. Liu, C. Zhang, H. Zhang, N. Zhao, Z. X. Yu and J. Xu, J. Am. Chem. Soc., 2017, 139, 8678-8684.

36 D. Fu, W. Pu, Z. Wang, X. Lu, S. Sun, C. Yu and H. Xia, J. Mater. Chem. A, 2018, 6, 18154-18164.

37 W. Denissen, M. Droesbeke, R. Nicolay, L. Leibler, J. M. Winne and F. E. Du Prez, Nat. Commun., 2017, 8, 7.

38 H. Z. Ying, Y. F. Zhang and J. J. Cheng, Nat. Commun., 2014, $5,9$.

39 Y. F. Zhang, H. Z. Ying, K. R. Hart, Y. X. Wu, A. J. Hsu, A. M. Coppola, T. A. Kim, K. Yang, N. R. Sottos, S. R. White and J. J. Cheng, Adv. Mater., 2016, 28, 7646-7651.
40 S. Zechel, R. Geitner, M. Abend, M. Siegmann, M. Enke, N. Kuhl, M. Klein, J. Vitz, S. Grafe, B. Dietzek, M. Schmitt, J. Popp, U. S. Schubert and M. D. Hager, NPG Asia Mater., 2017, 9, e420.

41 H. Kim and M. W. Urban, Langmuir, 2000, 16, 5382-5390.

42 L. Yang, Y. L. Lin, L. S. Wang and A. Q. Zhang, Polym. Chem., 2014, 5, 153-160.

43 X. Y. Jia, J. F. Mei, J. C. Lai, C. H. Li and X. Z. You, Chem. Commun., 2015, 51, 8928-8930.

44 X. Y. Jia, J. F. Mei, J. C. Lai, C. H. Li and X. Z. You, Macromol. Rapid Commun., 2016, 37, 952-956.

45 C. H. Li, C. Wang, C. Keplinger, J. L. Zuo, L. Jin, Y. Sun, P. Zheng, Y. Cao, F. Lissel, C. Linder, X. Z. You and Z. A. Bao, Nat. Chem., 2016, 8, 619-625.

46 Y. L. Rao, A. Chortos, R. Pfattner, F. Lissel, Y. C. Chiu, V. Feig, J. Xu, T. Kurosawa, X. D. Gu, C. Wang, M. Q. He, J. W. Chung and Z. N. Bao, J. Am. Chem. Soc., 2016, 138, 6020-6027.

47 J. F. Mei, X. Y. Jia, J. C. Lai, Y. Sun, C. H. Li, J. H. Wu, Y. Cao, X. Z. You and Z. N. Bao, Macromol. Rapid Commun., 2016, 37, 1667-1675.

48 F. B. Madsen, L. Y. Yu and A. L. Skov, ACS Macro Lett., 2016, 5, 1196-1200.

49 J. Zhao, R. Xu, G. X. Luo, J. Wu and H. S. Xia, J. Mater. Chem. $B$, 2016, 4, 982-989.

50 J. Zhao, R. Xu, G. X. Luo, J. Wu and H. S. Xia, Polym. Chem., 2016, 7, 7278-7286.

51 X. Z. Yan, Z. Y. Liu, Q. H. Zhang, J. Lopez, H. Wang, H. C. Wu, S. M. Niu, H. P. Yan, S. H. Wang, T. Lei, J. H. Li, D. P. Qi, P. G. Huang, J. P. Huang, Y. Zhang, Y. Y. Wang, G. L. Li, J. B. H. Tok, X. D. Chen and Z. A. Bao, J. Am. Chem. Soc., 2018, 140, 5280-5289.

52 J. C. Lai, J. F. Mei, X. Y. Jia, C. H. Li, X. Z. You and Z. A. Bao, Adv. Mater., 2016, 28, 8277-8282.

53 Y. Yang, E. M. Terentjev, Y. Wei and Y. Ji, Nat. Commun., 2018, 9, 2291.

54 J. C. Lai, L. Li, D. P. Wang, M. H. Zhang, S. R. Mo, X. Wang, K. Y. Zeng, C. H. Li, Q. Jiang, X. Z. You and J. L. Zuo, Nat. Commun., 2018, 9, 2725. 